\title{
The Impact of Statistics in Industry and the Role of Statisticians ${ }^{1}$
}

\author{
Ronald J.M.M. Does* and Albert Trip ${ }^{+}$ \\ * Institute for Business and Industrial Statistics, University of Amsterdam \\ + IBIS UvA BV and Philips Semiconductors, The Netherlands
}

\begin{abstract}
The use of statistics in quality management has a long history. Pioneers in this field, such as Walter A. Shewhart and W. Edwards Deming, refer to themselves as industrial statisticians. Statistical thinking in industry means that all work is regarded as a series of interconnected processes, that all processes show variation, and that a reduction in variation is the key for continuous improvement. In literature we find several quantitative quality programs to achieve this. We may mention Statistical Process Control (SPC) and the Six Sigma quality program, among others. We have implemented Statistical Process Control and Six Sigma in several industries. In this paper we briefly describe the philosophies of both programs and the steps needed for a successful implementation. Based on practical experience with both programs we describe the role that a statistician can play in industry. We shall also give an overview of research initiated by the projects we have carried out.
\end{abstract}

Key words: Statistical Process Control; Six Sigma; Statistics in Industry

\section{Introduction}

Quality management involves managing, controlling, and reducing variation. Traditionally this has been the domain of statistics, and hence variation is both the actual link between quality management and statistics, and the reason for the wide use to which statistical methods have always been put where quality problems are concerned. In situations where statistical methods have long been used, efficiently tackling and solving quality problems, statistical thinking (cf. Snee, 1990, and Hoerl, 1995) primarily forms the basis for continuous quality improvement, one of the core elements of Total Quality Management (TQM). Statistical thinking is based on the assumption that all activities can be regarded as processes, that all processes display variation, and that improvements are achieved by a strategy directed at reducing this variation. In other words, the concept of statistical thinking means (cf. Hoerl, 1995):

1. All the work is realized in a system of mutually connected processes, each having a customer/supplier relationship;

2. All processes show variation;

3. The observed variation can be divided into variation due to common causes and variation due to special causes;

\footnotetext{
${ }^{1}$ This article has been based on an invited lecture that was presented by the first author at the Österreichische Statistik-Tage 2000 in Innsbruck.
} 
4. Understanding the origin of both sources of variation is the key to reducing variation;

5. Reducing variation is, in its turn, the key to quality improvement, productivity and profitability.

Hence, variation reduction is considered to be a key subject in modern quality control and improvement. W. Edwards Deming said it in the following way "If I had to reduce my message for management to just a few words, I'd say it all had to do with reducing variation" (cf. Neave, 1990). The language of variation is best understood by making use of statistics and this explains the free use always made of statistical methods and techniques within quality management. In literature several quantitative approaches to reducing variation are suggested. They range from complete stepwise approaches to tools and methodologies. Two complete stepwise approaches will be discussed in this paper, viz. Statistical Process Control (SPC) and Six Sigma. The reason for this choice is that the first one (SPC) has a very long tradition in the quality world and the second has a big impact nowadays. Practical experience can only be obtained by implementing the programs in industry. Although we work at a university, we were given the opportunity to start with a consultancy unit within the Faculty of Mathematics and Computer Science in 1994. Since 1998, the unit has been embedded in the Holding of the University of Amsterdam, in which all the commercial activities of the university are accommodated. The unit is called the Institute for Business and Industrial Statistics and is abbreviated by IBIS UvA BV. The services that are provided are the implementation of SPC, Six Sigma and a related Business Improvement Program, among others. Currently, there are eight enthusiastic consultants employed. To support and constantly improve the consulting activities, the group aims at contributing to scientific research in business and industrial statistics on an international level and to promote the application of industrial statistics in all relevant parts of society.

This paper is organized as follows. In the next two sections we describe the two programs (SPC and Six Sigma). Then we discuss the role a statistician can play in industry.

\section{Statistical Process Control}

Statistical Process Control (SPC) has become an important part of quality control activities. SPC is definitely accepted as one of the main tools of quality management in industry, and also in service organisations. All the more remarkable is even today there are still many companies denying themselves the benefits of SPC. The novelty of SPC cannot be the reason, because its history (see e.g. Duncan, 1986) begins already in 1924, when Walter A. Shewhart of the Bell Telephone Laboratories sketched the first modern control chart; he published his findings in 1931 (Shewhart, 1931). Acceptance of the new technique by other companies went with ups and downs from the very beginning. There was a great breakthrough when W. Edwards Deming introduced SPC and other quality control techniques in Japan, immediately after the Second World War. The success of the Japanese economy made American business in the 1980's aware of these techniques, which were then readily adopted. They subsequently spread to Europe as well. In his 
long career Deming observed many reasons for the slow acceptance of SPC (Deming, 1986). Among managers he noticed a focus on short-term results, and trust in systems, figures, targets, computers, specifications, and (quality) programs. Managers often lacked vision and leadership. That's why Deming in the 1950's developed the concept of what is now called "Total Quality Management", and why he formulated fourteen points - to serve as guidelines for management - aimed at creating a better environment for the process of improvement. A fundamentally different view on management was introduced: of course managers need to care greatly about the results, but they need also be involved in developing better methods to achieve better results. Other ingredients for achieving higher quality with lower waste (customer focus, reengineering, just-in-time production, etc.) were developed, and in the 1990's the need for a framework was satisfied by Brian L. Joiner. Much of his "Fourth Generation Management" (Joiner, 1994) is the product of Deming, as Joiner readily concedes. In Deming's view acceptance of SPC is thus very much management's responsibility. His solution for a better acceptance was to improve the level of management, and so he introduced Total Quality Management. This concept was clearly successful, first in Japan and then in the United States of America, and Europe.

Approaches for implementing SPC can hardly be found in literature, however. Many descriptions focus on the tools of SPC (e.g. Duncan, 1986; Montgomery, 1996; Wheeler and Chambers, 1992), and there are also some papers focusing on organisational aspects of implementation (e.g. Parks, 1983 and 1984; Gaafar and Keats, 1992). This section summarizes a framework for implementation of SPC, including both methodological and organisational aspects. Full details can be found in Does, Roes and Trip (1999a).

Confusion about the exact meaning of SPC may be a reason why a comprehensive view on its implementation is lacking. Often SPC was equated with control charts, but nowadays it is clearly recognised that the control chart is just a methodological tool. This section presents SPC as a hands-on approach, a coherent set of activities to analyse, improve and monitor processes. The approach is based on statistical thinking. SPC generally starts in production departments, but the concept can be used for all processes (e.g. designing processes and products, administration, purchasing). The framework for implementing SPC will without loss of generality primarily be directed towards production processes. In addition we will describe how company-wide implementation of SPC sets the stage for Total Quality Management (TQM). Based on our own experience with implementing SPC, we can mention the following problems:

1. It takes several years to implement SPC company-wide.

2. Constant attention and support of executive management are required.

3. SPC calls for delegation of tasks, responsibilities and qualifications to the lowest possible level.

4. implementation of SPC has to be guided by an expert with thorough knowledge of the possibilities and problems of statistics.

5. The organisation has to be familiar with tackling problems through the use of data. 
6. Teamwork and a project management approach are essential.

These problems arise especially when the implementation is concentrated on the methodological aspects of SPC. More attention to organisational aspects might well avoid such problems. This requires careful planning of the implementation phases, as well as a suitable organisational structure. How exactly a company is organised is not really important for introducing SPC - in principle any organisation is suitable, although an organisation based on e.g. sociotechnical principles (cf. Haak, 1994) is better suited than many others. There's a good chance, however, that an organisation that has successfully implemented SPC along the lines described in this section, will have changed considerably. The beginning of the implementation of SPC in a company generally starts with an orientation period, when executive management learns about the basics of SPC and becomes aware that SPC may contribute to the company's bottom line. External influences, such as the insistence of a customer that SPC should be implemented, may play a role in this process. Philips Semiconductors, for example, started introducing SPC because the American automotive industry urged the company to do so. After executive management has been convinced to use SPC, the implementation is divided into the following four phases (cf. Does, Roes and Trip, 1999a):

- Phase 1: Awareness;

- Phase 2: Pilot projects;

- Phase 3: Integral implementation in production;

- Phase 4: Setting the stage for Total Quality.

The organizational structure that we use to implement SPC consists of Process Action Teams and a Steering Committee. A Process Action Team has the assignment to bring the process in control using a ten-step activity plan, which is the methodological part of the framework. Such a team usually consists of: 2-5 operators, a foreman, a process engineer, a maintenance engineer and an SPC-expert. They should represent all disciplines directly related to the process. Team members receive a training-on-the job when using the tenstep activity plan. The ten steps of the activity plan can be grouped around the main purposes of SPC:

- steps 1-3: describe the process and trace potential weak points;

- steps 4, 5: search for improvements for weak points;

- steps 6-8: define effective measurements and control loops;

- steps 9, 10: assess the performance and arrange for continuous improvement.

In Does, Roes and Trip (1999a) the ten-step activity plan is described in full detail. Top Management should show commitment and should delegate the management of the implementation to a Steering Committee. Top Management monitors the progress on basis of reports from this committee and feedback sessions with the Process Action Teams. 
The main tasks of the Steering Committee are: steering, facilitating, promoting and reporting. The committee consists of the managers of the departments involved (cf. Does, Roes and Trip, 1999a).

Practical experience with this way of implementation was acquired through active involvement in various projects. We have implemented SPC in mass production, e.g. Sara Lee - DE (coffee and tea) and Philips Semiconductors (diodes), in small batch production, e.g. Thomson-CSF - Hollandse Signaalapparaten (Printed Circuit Boards) and Fokker Aerostructures (cable harnesses and machining) and also in low volume production of complex products, e.g. ASM Lithography (wafer steppers).

We conclude this section by noting that some statistical issues we have encountered during the implementation of SPC, are very challenging. We have published several papers on real-life problems which were a direct consequence of our participation in the projects (cf. Roes and Does, 1995; Does, Roes and Trip, 1999b; Roes, Does and Jonkers, 1999).

\section{The Six Sigma Quality Program}

Six Sigma is a Total Quality Management program. It is a customer-driven approach to obtain a higher level of quality and it provides an overall framework for quality management. Sigma is a letter from the Greek alphabet and is used in statistics as the symbol for the standard deviation. The goal of Six Sigma is to obtain defect rates of less than 3.4 defects per million opportunities. The Financial Times of October 10, 1997 defines the Six Sigma initiative as "A program aimed at the near-elimination of defects from every product, process and transaction". This Six Sigma initiative is linked to financial performance, which makes it a popular program in the United States of America: "Wall Street loves Six Sigma". The Six Sigma philosophy and methodology were developed at Motorola in 1987. The CEO of this company, Bob Galvin, formulated in that year a new, visionary quality goal to all Motorola employees (cf. Bhote, 1989):

- Improve product and service quality 10 times by 1989 .

- Achieve at least a 100-fold improvement by 1991.

- Achieve Six Sigma capability by 1992.

- Spread dedication to quality to every facet of the corporation, and achieve a culture of continual improvement to assure total customer satisfaction.

It was such a successful approach to quality management that they won in 1988, as one of the first companies, the Malcolm Baldrige National Quality Award. In 1997 at Motorola 5,000 teams are involved in the program, incorporating roughly 65,000 of the 142,000 employees of Motorola, and they claim 2.4 billion dollars savings a year (cf. Klaus, 1997). Recently, other companies like American Express, AlliedSignal, Black \& Decker, Boeing, City Bank, Ericsson, Ford, General Electric, Lockheed-Martin, Nokia, Paccar, Polaroid, Sony and Texas Instruments started with the implementation of the Six Sigma program as well. In the editorial of the May 1997 issue of Quality Progress we 
read that General Electric invested in 1996200 million dollars in the program and saved around 150 million dollars. In 1997 they have invested 300 million dollars and saved 450 million dollars. In 2000 General Electric should be company-wide at a Six Sigma level and the visionary leader of General Electric, Jack Welch, expects cost savings of several billions dollars.

Aims/reasons (and proved results) of Six Sigma are: more satisfied customers, more profit, less rework and unnecessary process steps, a higher yield, less waste and emission. Therefore is needed leadership and stretched goals and employee training with smart structure.

Since 1996, IBIS UvA has been involved with the implementation of Six Sigma at General Electric Plastics Europe. We have also implemented the program at the following companies: NEMEF, a Black \& Decker company (the Netherlands), Perlos Oyj (Finland) and DAF Trucks, a Paccar company (Belgium and the Netherlands). However, Six Sigma is a legally protected program. Consequently, it is not possible to discuss all elements in full detail. We shall base our introduction on the books of Harry (1997) and Harry and Schroeder (2000) in which the basic information of Six Sigma and the strategy to implement the program can be found.

Typically, Six Sigma starts with a strong commitment from top management. They are the first to receive an executive training in the methodology. The result of the training should be that the top management is convinced of the need for Six Sigma and that the necessary means will be available. Next, other managers will follow a similar seminar. Management forms a group which will be called Champions. They are responsible for the availability of resources and organisational issues.

Subsequently, a number of pilot (Six Sigma) projects are defined by the Champions. These projects are chosen according to a promising decrease in defects or equivalently, an increase of the sigma level of a certain customer's Quality Characteristic (QC). All these projects are lead by so-called Black Belts (BB's). They are responsible for measuring, analyzing, improving and controlling the key processes that influence the customer's QC such that the process becomes Six Sigma. To enable the BB's to achieve their reduction in defect rates, intensive training has to be given. Such a training consists of 4 modules. Each module takes a week and the period between the modules is 3 weeks. The BB's are trained in understanding the road map, statistical tools and social skills needed to successfully complete their project. A BB, who should be fully dedicated to the Six Sigma program, has to work on his project between the four training modules, thereby following the newly learned steps and applying tools of Six Sigma.

Every step is evaluated by a reviewer, which is called Master Black Belt (MBB). The task of a MBB is to train and mentor the BB's and to review projects. After successfully finishing the pilot projects, other projects may be started. New BB's are trained and the educated BB's continue doing new projects, after finishing their first one. After a while the whole organization is involved in Six Sigma. The BB's and MBB's are full time involved in the Six Sigma program, while other people (the so-called Green Belts) cooperate when necessary. Also training for the shop floor employees (called Yellow Belts) should be available such that all people in the company become acquainted with and committed to Six Sigma. This aids BB's to finish their projects and to maintain the results. A result of Six Sigma is that throughout the whole organization decisions are based on quantitative 
facts and not on emotions or feelings.

To obtain goals like 3.4 defects per million opportunities, projects are selected based upon external customer's QC. The roadmap to achieve this is called the "Six Sigma Breakthrough Strategy" by Harry (1997). This strategy consists of four phases: Measurement, Analysis, Improvement and Control (i.e. the four modules just mentioned) and is abbreviated by MAIC.

The first phase "Measurement" is concerned with selecting and defining a project, based upon a to the customer important QC. It is important to select a project that is workable, hence not too large and not too small. Next, one should translate the external characteristic to an internal characteristic which is measurable in the process. The relation between external and internal characteristic should be very clear. The precise definition and selection of the project and the translation of external QC into internal QC are very important and critical for the success of the project. In addition, in order to be able to evaluate the improvements properly, the measurement system of the internal QC has to be analyzed. In practice we have encountered many problems with the standard measurement system analysis according to e.g. AIAG (1990). It has generated new research, e.g. comparison of Random or Fixed Observers (see Van den Heuvel and Trip, 2000) and extensions to some nonstandard situations (see Van den Heuvel, 2000).

The second phase "Analysis" is concerned with determining the process capability. In this phase the distinction between short-term and long-term variation is made. It helps the BB's to decide which variation part needs to be worked on to obtain the Six Sigma goal. Also the selection of the important factors that influence the internal characteristic is made. In some cases, it is necessary to redesign the product and/or process. From a statistical point of view this phase is interesting. Selection of sources of variation can be done with an upgraded graphical tool, the so-called Multi-Vari chart (see De Mast, Roes and Does, 2000). Also enhancements of the control charts are in this phase relevant (see Koning and Does, 2000).

The next phase is called "Improvement". The goal is to improve the performance of the internal characteristic. To do this a mathematical relation between the important factors and the characteristic is established with statistically designed experiments. From this relation optimal settings and levels can be derived. Also the specifications should be clear after completion of this stage.

The fourth and last phase "Control" is concerned with keeping the process controlled at the new settings. This phase uses also a lot of SPC tools. The idea is to institutionalize the process changes by documenting and monitoring. After a period the process should be reassessed.

When this strategy - Measurement, Analysis, Improvement, and Control - is completed for all key processes within a company, breakthrough improvement occurs in economics and customer satisfaction. We note that the Six Sigma program is not typical an improvement program for Operations. All other departments from Marketing through Human Resources participate in the approach from the start.

As mentioned before the Six Sigma program is legally protected and in several ways typical American. This was the reason that we have developed our own program (cf. De Mast, Schippers, Does and Van den Heuvel, 2000). We have called this the Business Improvement Program and it was carried out for the first time in the period September 1998 
until June 1999. Sixteen project leaders from a large company in the food industry in the Netherlands (i.e. Douwe Egberts, a Sara Lee company) were selected to run the program. Six different plants of the company were involved. The project leaders worked in Engineering, Operations, Packaging, Product Development, Purchasing and Technology. In the period mentioned they were able to work two days per week on their projects. In total eleven of them succeeded in finalizing the project. The average revenue per project was 200,000 dollars savings per year. The company has decided to continue with this program. Also other companies in the Netherlands are enthusiastic about this approach and several companies have started.

\section{A Statistician in Industry}

The role of statisticians in industry is for many years a source of anxiety. In this section we review some papers about this topic, and give comments based on our own experience as SPC and Six Sigma experts and statistics consultant.

Snee (1991) gave his view on the role of the statistician within the context of Total Quality, a program in which statistics is only one aspect. He distinguished different roles according to whether or not the statistician, his client, and the organisation are passive or active (see Table 1).

\begin{tabular}{|c|c|c|c|c|c|}
\hline \multirow{2}{*}{\multicolumn{2}{|c|}{$\begin{array}{l}\text { Organisation } \\
\text { Client }\end{array}$}} & \multicolumn{2}{|l|}{ Passive } & \multicolumn{2}{|l|}{ Active } \\
\hline & & Passive & Active & Passive & Active \\
\hline \multirow[t]{2}{*}{ Statistician } & Passive & None & Helper & Teacher & Data blesser \\
\hline & Active & Crusader & Colleague & Leader & Collaborator \\
\hline
\end{tabular}

Table 1: Different roles of the statistician.

Snee's opinion is that in order to survive the statistician should seek an active role, whether his organisation is passive or active. Especially in organisations that actively pursue Total Quality, statisticians can only be of real help when they influence management as leaders or collaborators, although good technical work is important as ever. So they need to learn the techniques of organisational development. According to Snee:

Understanding the behavioural aspects of statistics and using organisational development techniques are the greatest opportunities and challenges facing statisticians today.

Unfortunately, many statisticians appear not to be equipped with the skills required to be effective in industry. Hoerl et al. (1993) give as most important reasons:

- a broadly set of values, attitudes and behaviours that do not support industrial needs;

- a reward and recognition system that reinforces these values;

- an inward focus on the profession; 
- a lack of emphasis on the fundamental role of statistics and its use in the scientific method;

- a consuming focus on tools and methods rather than the use of statistics in a systematic approach to solve problems and make improvements.

The authors recommend a set of nonstatistical skills:

- solid grounding in the fundamentals of modern quality principles;

- basic understanding of the economic and technical issues of the business;

- knowledge of the field of organisational effectiveness;

- consulting and training skills.

They also give advice on the necessary statistical skills to survive, as well as suggestions on literature to acquire all skills. Related to the statistical skills their general theme is the need to understand how to apply statistical methods to solve real problems. In a challenging paper Banks (1993) reinforces the latter theme:

Companies must have access to Ph.D. level statisticians internally, who may not be developing new theory, but can comfortably command the old.

Banks refers to the Japanese practice of dealing with statistical methods:

I would guess that intelligent use of simple tools will achieve about $95 \%$ of the knowledge that could be obtained through more sophisticated techniques, at much smaller cost. Also the simple tools can be applied more quickly to all problems, whereas the complex tools are unlikely to be ubiquitously used.

His recommendations for industrial statisticians are more or less equal to those of Hoerl et al. The author also compares industrial statistics with academic statistics, and notes that the greatest gulf of all between the two is one of respect. He noticed that some academic statisticians regard most industrial statisticians as the ones who were not good enough to succeed at a university, while applied statisticians are often openly sceptical of academics' practicality. He fears that these divisions cannot be repaired easily, but hopes that universities design curriculums that take better account of the needs of applied statisticians. After all, that's what the majority of their Ph.D. and Master's students will be.

In his comment Hahn gives a description of the industrial statistician:

Graduates suited for industry are likely to become impatient with the academic environment and slow pace of the university. High grades is one of the things that we, in industry, look for in candidates - but it is only one of many. We need excellent communicators (who can talk in their customer's language, rather than in statistical jargon), good listeners, hard workers, team players and fast learners. We look for people who are enthusiastic, who are 
willing to work simultaneously on multiple projects, who are self-confident - without being arrogant, who can rapidly diagnose a problem and see the big picture, who are willing to ask fundamental questions and challenge assumptions, who are good at selling projects and themselves, who can cope with frequent management reviews and changes of direction - and who are still cheerful at the end of the day. It is not an environment that is conductive to proving theorems - but it is hectic and exciting!

With so much attention to nonstatistical skills, we might easily forget that statistics is still the core competence of a statistician. Gunter (1998) warned strongly for watereddown quality, and quality professionals without a specific set of core skills. But he blames statisticians for sticking to the 'now archaic and simplistic' control charts, while there are so many new and powerful methods:

We have become a shockingly ingrown community of mathematical specialists with little interest in the practical applications that give real science and engineers their vitality.

Gunter notices that the computer science is eager to step into the breach.

Hahn and Hoerl (1998) notice also that the impact of computer science on statistics is large. In the first place is the accessibility of statistical software responsible for the "democratisation of statistics". Then there is the fact that various new approaches for data analysis were introduced (e.g. neural networks, fuzzy logic and data mining), often independently of the statistical community. And finally, we now have the opportunity to work with management information systems. In this world of "statistics without statisticians" the unique value of the statistician may - according to Hahn and Hoerl — bring:

an 'improvement' mindset — based on proactive avoidance of problems to the team and the ability to take a holistic approach to problem definition and resolution, as well as our critical quantitative skills.

Meyer, Trost and Vukovinsky, commenting on Hahn and Hoerl, pose the question whether we are facing a shortage of effective consulting statisticians:

Our field has not been wildly successful in attracting individuals who innately have the characteristics it takes to be effective. Statisticians, as a group, tend to be introverted. It is not likely that an introvert can be trained to be an extrovert. Therefore, the statistical profession should step up efforts to recruit more dynamic individuals to the field. Unfortunately, there is much competition, and these individuals are likely to be attracted to fields that appear to be more exciting or have better pay.

These authors see conflicts with the theoretical rigours of the typical statistics Ph.D. program at universities. Many students stop at a master's degree, and others get their statistics doctorate in a user-friendlier department (such as industrial engineering).

We are aware that all observations are from American authors. We have a strong feeling, however, that the situation is largely the same in Europe. The perceived inward focus 
of the statistical community e.g. is in our opinion perfectly illustrated with a discussion in the Netherlands Society for Statistics to introduce a certification system for statisticians. Traditional statisticians felt threatened by the "democratisation of statistics", and wished to limit the harmful influence of dabblers. We are sure that clients are well able to distinguish the good from the bad statisticians. Moreover, good and bad might well be defined differently by different types of statisticians. Another aspect of the inward focus of the statistical community is the reaction towards new methods from outside. The denouncing in the past of the methods of Taguchi is telling. And these days many statisticians appear to dissociate themselves from the success of the "Six Sigma" program of Mikel J. Harry, even though several world-class companies use it.

A closer co-operation between industry and academia would be useful in Europe as well. The gap between academic and industrial statistics exists here too. For this reason we think that it might be a good idea to recruit industrial statisticians among industrial engineering students, although this is not without problems. The founding of a consulting unit at a university, like IBIS UvA BV, is another improvement. This is certainly useful for the education of students, for research in applied statistics, for the possibilities of its co-workers to improve their skills, and for the industry to get expert statistical support and reap the fruits of the latest developments in the field. We deem ourselves fortunate to have the opportunity to work for IBIS UvA, and we are sure that the employer in Stadskanaal of the second author benefits from his experience. For a statistician in industry it is useful to coach students in research or application projects, and we believe that giving lectures for students is also very important. That the statistician needs good training and communication skills is beyond doubt; he won't succeed in his own company if he has none.

We totally agree with all authors who stress the need for nonstatistical skills. But Gunter has a valid point when he argues that the core skills still are the basis. Otherwise it would be difficult to put the occasional hypes in the right perspective. For example, within Philips there was a period that "World Class Quality" (Bhote, 1991) used to be hot. The indiscriminate user would have followed the trend, disregarding the many opportunities from traditional experimental design theory. Especially in the rather complex world of semiconductors industry this would have led to many disappointments.

Regarding statistical software we have the experience that many problems can be solved with simple tools. The statistical possibilities of (simple) programs like Minitab or even Excel might often suffice. In this respect we again fully agree with Banks' comments on simple tools. A statistician needs more specified statistical software, but the ordinary person does not. Most output will be inconceivable anyhow. The trend that enormous amounts of data are available for analysis is clearly recognisable. This requires new methods and skills for statisticians, as Gunter, Hahn and Hoerl, rightly observe. Our experience is that it is still a difficult matter to combine the relevant data from the separate databases all over the organisation. Knowledge of database management might well be a useful skill for a statistician.

We conclude this section with some remarks about the career of a statistician. We think that for many it may well be a lifetime job; however, the average industrial statistician wants occasionally new challenges. For some the ever-changing world will offer enough of these, but many (and especially those Meyer et al. are hinting at) will need 
more. We can certainly recommend a part-time job at an outside consultancy agency or university. On the other hand, being a part of a large company offers also opportunities for more or less closely related activities within the company. A truly active statistician will notice that several things can be done in all sorts of disciplines, quality, organisation, logistics, etc.

For a statistician in industry the booming interest in the Six Sigma quality program offers great opportunities. There is no other quality program, not even Total Quality Management, with such a strong emphasis on statistical thinking and statistical methods. Statisticians working in the context of Six Sigma therefore deal with an active organisation and active clients (the 'black belts' and so on). According to Table 1 they can therefore choose between a passive role as 'data blesser' or an active role as 'collaborator'. In the second role the nonstatistical skills described by Hoerl et al. (1993) will be badly needed, whereas in the former case a profound statistical knowledge suffices.

We have no doubt that the only appropriate role for statisticians is the 'collaborator' because their unique value (as defined by Hahn and Hoerl, 1998) can only then find expression. And for most statisticians this role will also give most satisfaction, because then they play their part at the centre of the organisation, with not just statistical problems to solve but business problems. For this kind of statistician it might be possible to become a Master Black Belt, although many might prefer the function of involved consultant.

\section{Acknowledgements}

The authors thank Professor Peter Hackl and Professor Gilg Seeber for inviting the first author to speak at the Österreichische Statistik-Tage 2000 and the Editor, Professor Dutter for stimulating to write this paper.

\section{References}

AIAG. Measurement Systems Analysis Manual. Automotive Industry Action Group, Detroit, MI, 1990.

D. Banks. Is industrial statistics out of control? (with comments). Statistical Science, 8:356-409, 1993.

K.R. Bhote. Motorola's long march to the Malcolm Baldrige National Quality Award. National Productivity Review, 8:365-376, 1989.

K.R. Bhote. World Class Quality. Amacom, New York, 1991.

J. De Mast, K.C.B. Roes, and R.J.M.M. Does. The multi-vari chart: A systematic approach. To appear in Quality Engineering, 2000.

J. De Mast, W.A.J. Schippers, R.J.M.M. Does, and E.R. Van den Heuvel. Steps and strategies in process improvement. Quality and Reliabilty Engineering International 16:301-311, 2000. 
W.E. Deming. Out of the Crisis. MIT, Cambridge, 1986.

R.J.M.M. Does, K.C.B. Roes, and A. Trip. Statistical Process Control in Industry. Kluwer Academic, NL-Dordrecht, 1999a.

R.J.M.M. Does, K.C.B. Roes, and A. Trip. Handling multivariate problems with univariate control charts. Journal of Chemometrics, 13:353-369, 1999b.

A.J. Duncan. Quality Control and Industrial Statistics (5th edition). Irwin, Homewood, 1986.

L.K. Gaafar and J.B. Keats. Statistical process control: a guide for implementation. International Journal of Quality and Reliability Management, 9(4):9-20, 1992.

B.H. Gunter. Farewell fusillade: an unvarnished opinion on the state of the quality profession. Quality Progress, 32(4):111-119, 1998.

A.T. Haak. Dutch Sociotechnical Design in Practice: An Empirical Study of the Concept of the Whole Task Group. Van Gorcum, NL-Assen, 1994.

G. Hahn and R. Hoerl. Key challenges for statisticians in business and industry (with discussion). Technometrics, 40:195-213, 1998.

M.J. Harry. The Vision of Six Sigma. Fifth Edition, 8 Volumes. Tri Star Publishing, Phoenix Arizona, 1997.

M.J. Harry and R. Schroeder. Six Sigma. Currency, New York, 2000.

R.W. Hoerl. Enhancing the bottom-line impact of statistical methods. ASQC Statistics Division Newsletter, 15(2):6-18, 1995.

R.W. Hoerl, J.H. Hooper, P.J. Jacobs, and J.M. Lucas. Skills for industrial statisticians to survive and prosper in the emerging quality environment. American Statistician, 47:280-292, 1993.

B.L. Joiner. Fourth Generation Management: the New Business Consciousness. Mc Graw Hill, New York, 1994.

L.A. Klaus. Motorola brings fairy tales to life. Quality Progress, 30(6):25-28, 1997.

A.J. Koning and R.J.M.M. Does. Cusum charts for the preliminary analysis of individual observations. Journal of Quality Technology, 32:122-132, 2000.

H.R. Neave. The Deming Dimension. SPC Press, Knoxville Tennessee, 1990.

D.C. Montgomery. Introduction to Statistical Quality Control, (3rd edition). Wiley, New York, 1996.

C.J. Parks. Statistical quality control: management's role. Manufacturing Engineering, 91(6):59-62, 1983. 
C.J. Parks. Workers response to SPC. Manufacturing Engineering, 92(1):59-60, 1984.

K.C.B. Roes and R.J.M.M. Does. Shewhart-type charts in nonstandard situations (with discussion). Technometrics, 37:15-40, 1995.

K.C.B. Roes, R.J.M.M. Does, and B.S. Jonkers. Effective application of Q-R charts in low-volume manufacturing. Quality and Reliability Engineering International, 15:175-190, 1999.

W.A. Shewhart. Economic Control of Quality of Manufactured Product. Van Nostrand Reinhold, Princeton, 1931.

R.D. Snee. Statistical thinking and its contribution to total quality. American Statistician, 44:116-121, 1990.

R.D. Snee. Can statisticians meet the challenge of total quality? Quality Progress, 24(1):60-64, 1991.

E.R. Van den Heuvel. Gage R\&R for nonstandard situations. In: 54th Annual Quality Congress Transactions. ASQ, Milwaukee, pp. 317-328, 2000.

E.R. Van den Heuvel and A. Trip. Evaluation of measurement systems for models with fixed observers. Submitted for publication, 2000.

D.J. Wheeler and D.S. Chambers. Understanding Statistical Process Control (2nd edition). SPC Press, Knoxville, Tennesee, 1992.

Authors' addresses:

Ronald J.M.M. Does

Institute for Business and Industrial Statistics

University of Amsterdam (IBIS UvA BV)

Plantage Muidergracht 24

1018 TV, Amsterdam

The Netherlands

Email: rjmmdoes@wins.uva.nl

\author{
Albert Trip \\ IBIS UvA BV and Philips Semiconductors \\ P.O. Box 10 \\ 9500 AA Stadskanaal \\ The Netherlands
}

